\title{
Integrating Engineering for Developing Communities into Engineering Edu- cation A Case Study
}

\section{Prof. Lupita Del Carmen Montoya, University of Colorado, Boulder}

Lupita D. Montoya is Assistant Professor in the Department of Civil, Environmental and Architectural Engineering at the University of Colorado, Boulder with courtesy appointment in the Department of Environmental and Occupational Health at the Colorado School of Public Health. She received a B.S. degree in Engineering (Mechanics) from California State University at Northridge. She holds a M.S. degree in Mechanical Engineering and a Ph.D. degree in Environmental Engineering from Stanford University. She conducted postdoctoral research in Environmental Health at the State University of New York and Harvard School of Public Health. At the University of Colorado, she leverages her multidisciplinary background and her social consciousness in her research and her teaching.

\section{Ms. Robyn Sandekian, University of Colorado Boulder}

Robyn Sandekian is the Managing Director of the Mortenson Center in Engineering for Developing Communities (MCEDC) at the University of Colorado Boulder (CU-Boulder). She earned BS and MS degrees in Aerospace Engineering Sciences at CU-Boulder in 1992 and 1994, respectively, then remained on campus to work for the Women in Engineering Program (WIEP). Ms. Sandekian joined the Engineering for Developing Communities Program (now known as the Mortenson Center in Engineering for Developing Communities) in spring 2004, just as the first EDC graduate track was approved.

With MCEDC, her main duties have included student advising and academic program development. In addition to her management role in the Mortenson Center, Ms. Sandekian has taught an Engineering Projects course around the theme of appropriate technology and conducted research on social entrepreneurship and sustainable community development in Nepal in 2008. Ms. Sandekian earned a Specialist in Education (Ed. S.) degree in Educational Leadership and Policy Studies from the University of Northern Colorado in May 2011 and began doctoral work in the Higher Education Student Affairs Leadership program there in fall 2011.

\section{Dr. Daniel Knight, University of Colorado, Boulder}

Daniel W. Knight is the engineering assessment specialist at the Integrated Teaching and Learning Program and Laboratory. He holds a BS in psychology from Louisiana State University, and an MS degree in industrial/organizational psychology and $\mathrm{PhD}$ degree in counseling psychology, both from the University of Tennessee. Prior to joining the University of Colorado at Boulder, he gained extensive experience in assessment and teamwork in an engineering education context through the development and evaluation of a team facilitation training course for engineering undergraduate students. Dr. Knight's research interests are in the areas of retention, program evaluation and teamwork practices in engineering education. His current duties include the assessment and evaluation of the ITL Program's hands-on undergraduate courses and K-12 engineering outreach initiatives. 


\title{
Integrating Engineering for Developing Communities into Engineering Education: A Case Study
}

\begin{abstract}
The present investigation is a case study of a first year design course with a survey and follow-up interviews to assess the experiences of students while in the classroom and during a follow-up trip to Peru to install the design. This mixed-methods study investigated the use of environmental engineering design for developing communities as the project topic in a first-year design course and specifically focused on the developmental effects on students who traveled to Peru to implement their design in a rural community. Data collected during an end-of-course survey and qualitative data garnered from interviews with three students who traveled to implement the design indicated that most students in the course gained an understanding of the concept of engineering for developing communities and found the topic more interesting than those offered in other course sections. Students who traveled gained deeper insight into both the topic and the challenges involved with working in developing communities. Students from both groups (travelers and non-travelers) noted an interest in pursuing future opportunities to work in developing communities, most likely through volunteer opportunities. Overall, results indicated that the course topic provided an effective context for learning about the design process, introducing unique aspects of engineering for developing communities, and motivating students to explore this topic further.
\end{abstract}

\section{Introduction}

The world faces engineering grand challenges ${ }^{1}$ in the coming years, and many of those will require input from skilled environmental engineers who have the motivation and persistence to work on large-scale, multifaceted problems. Engineering education needs to prepare today's students for the work they will do to meet global challenges. Perhaps the most daunting environmental task of our time is identifying effective and sustainable ways to decrease the number of individuals who lack access to clean water and improved sanitation facilities. While the need for environmental engineering problem solvers grows, so does the future employment opportunity for current students who choose this discipline. The U.S. Department of Labor Bureau of Labor Statistics estimates a 22\% growth of job opportunities in environmental engineering between 2010 and $2020 .^{2}$ Engaging first year engineering students in design has proven to be an effective way to increase academic achievement and persistence, ${ }^{3,4,5}$ as has introducing the concept of engineering as a "servant of society.",

Within engineering education, the typical method of implementing service to society is through service-learning, which is defined as "a teaching and learning strategy that integrates meaningful community service with instruction and reflection to enrich the learning experience, teach civic responsibility, and strengthen communities." 7 Service-learning in an international context, especially within developing communities, can be used to engage students who may not be as interested in design projects that do not have a socially-useful purpose. Fulfilling communitybased design needs contextualizes engineering education to make it relevant to first-year students, especially those underrepresented in STEM, in ways that basic theory courses including physics and calculus do not. 
The need to contextualize engineering education. African Americans, Latinos, and Native Americans in the US share some common cultural aspects in their leadership models. In particular, their leadership styles are usually people-centered, community-focused, and advocacy-oriented. ${ }^{8,9}$ Social and behavioral science studies have examined how core cultural values translate into career choices in these populations. For example, a recent study found that African American medical school graduates from historically black universities, like Howard and Morehouse, selected to work in communities of color immediately after graduation and chose general practice over specialties at much higher rates than their white counterparts chose. ${ }^{10}$ For American Indians, the likelihood of success in higher education is increased when the educational process is linked to their everyday life experiences and natural environment. Their continuing academic engagement is then apparent in their desire to pursue degrees or jobs that directly and indirectly benefit their native communities. ${ }^{11}$ Similarly, a study found that highly educated Latinas displayed a strong sense of commitment to follow career paths that served their communities. $^{12}$

Latinos are now the fastest growing demographic group throughout the US and are projected to comprise $29 \%$ of the population by 2050 , as compared with $15 \%$ in $2007 .{ }^{13}$ Unfortunately, this expected growth in population does not align with a similar expected growth in their representation in science, technology, engineering, and mathematics (STEM) fields. ${ }^{14}$ In spite of long and concerted efforts to recruit and graduate Latinos and other underrepresented minorities into these fields, their numbers are still low. Given this expected increase in population, STEM educators, administrators, and policy makers continue to search for innovative ways to engage these populations in STEM career paths. One promising method for increasing student interest and retention in engineering appears to be an early introduction to design. ${ }^{15}$

Encouraging the development of social skills that engineers need. In recent years, the concept of grit, defined as the ability to persevere and sustain passion for long-term goals, has gained attention from researchers trying to understand the traits that may dictate students' success. ${ }^{16}$ Grit was found to successfully predict educational attainment, grade point average, and retention. ${ }^{16}$ Another study found that engineering students who were female and/or NCAAathletes had higher levels of grit than other students did. ${ }^{17}$ The work by Carol Dweck on the fixed- versus growth-mindsets has also shed light onto specific behaviors that can lead to higher levels of achievement. ${ }^{18}$ Characteristics of growth mindsets, such as the ability to embrace challenges and persist in the face of setbacks, are essential components of grit. Engineering educators can implement teaching techniques leveraging knowledge on grit to create engineers capable of effectively addressing the increasingly complex needs of the $21^{\text {st }}$ century.

Notably, the student population drawn to engineering often includes those with successful academic backgrounds that have been attributed to "natural talent." Initial introduction to the rigors of an engineering curriculum often requires additional skills that students may or may not have (e.g., good study habits, time management, stress management) in addition to the common challenges of living on their own for the first time. How they respond to those challenges will likely define their future success. Classroom activities can be tailored to develop and reinforce grit in students and such activities should fit the context of the course. This paper presents results of the implementation of a pedagogical model using environmental engineering for developing communities as a topic of a first year design course and specifically focuses on the 
developmental effects garnered by students who traveled to Peru to implement their design in a rural community.

\section{Background}

First-year Engineering Projects (FYEP) is an interdisciplinary hands-on design/build/test course for entry-level engineering students and those who are considering changing their major to engineering. ${ }^{19}$ Through this course, students put engineering theory into practice early in their undergraduate years by working in teams to design, build, and test new products and inventions. Longitudinal studies on engineering student retention have shown consistent gains in retention for students participating in FYEP compared to students who did not participate in the course. ${ }^{15}$ Figure 1 shows data from the first 11 years (1994-2005) of offering the FYEP course at our institution and demonstrates the 6-year graduation rates associated with participation in that course. Six-year graduation rates shown are for students who enrolled in the course between 1994 and 2005. Findings showed statistically significant improvement in graduation rates within all categories that included a sufficient number of students (men, women, Caucasians, and Asians).

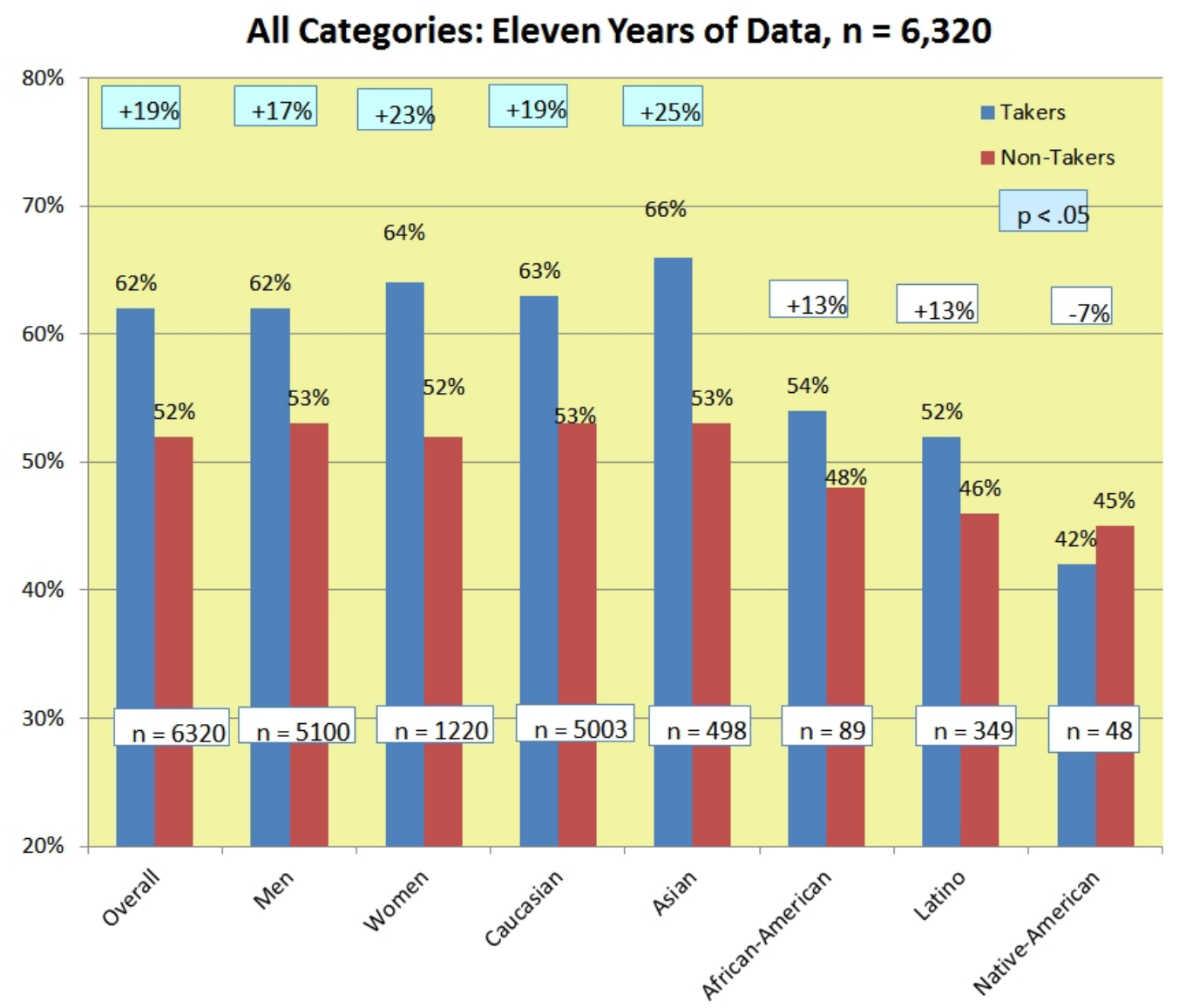

Figure 1 Historical graduation rates for FYEP course takers and non-takers, 1994-2005

Latino and African American students also demonstrated large gains in graduation rates, but due to their low representation, those gains were not statistically significant. Since Latino students currently comprise only about $10 \%$ of first-year engineering majors at this university, ${ }^{20}$ numbers 
are likely to remain small for the near future. Table 1 shows the percentage of Latino students enrolled in each of the six FYEP course sections. For reference, during the semester under investigation, enrollment across all six sections of the course included 13 Latino students among the 160 students total.

Description of the specific class involved in this study. The class described here is one of many sections of a first-year design course offered at our institution. The instructor opted to focus on design for developing communities as a means to make design both accessible and relevant to her students. The concept of accessibility applies to both the designers as well as the customers: the designers are students with limited technical knowledge and the customers have limited resources to pay for the design. The design is relevant because it must address the need of a real customer. In the process of developing the design, students learn about non-technical factors that may determine the success of their design implementation. In this case, the students were asked by representatives from an elementary school in rural Peru to design a solar water heater for a school bathroom. The implementation of a final design was made possible using funds raised from several sources within our institution.

\begin{tabular}{|l|c|}
\hline Course Section & $\begin{array}{c}\text { Percent of Overall } \\
\text { Latino Enrollment }\end{array}$ \\
\hline Study Section & $23 \%$ \\
\hline Alternate Section 1 & $23 \%$ \\
\hline Alternate Section 2 & $15 \%$ \\
\hline Alternate Section 3 & $15 \%$ \\
\hline Alternate Section 4 & $15 \%$ \\
\hline Alternate Section 5 & $8 \%$ \\
\hline
\end{tabular}

Table 1 Latino population within individual course sections during spring $2011(\mathrm{n}=13)$

A prime opportunity to demonstrate the power of grit presented itself during this class. Briefly, the instructor submitted a small grant proposal to fund the implementation of the best design from this section. The proposal was disqualified for technical reasons but was later resubmitted for a larger proposal competition and eventually funded. The initial disappointing experience was shared with the students to illustrate that setbacks are common in all facets of life but perseverance often pays off. Once funding was available for two students to travel to Peru for actual design implementation, student interest in their projects and personal motivation seemed to increase. Specifically, student teams wanted aspects of their design to be selected as the best for implementation, and individual students wanted to be chosen to travel to Peru and carry out the work.

The instructor carefully considered the selection of both the design and students who would travel to build the water heater. The final design was to incorporate the best features from all the 
designs in the class. Students interested in traveling were asked to provide statements on why they were good candidates. They also had to agree to continue working, without pay, on the final design after the class was over. Several students expressed interest and professed their commitment, but only a few ultimately performed the expected work. Students volunteered over ten hours per week for several weeks before the trip. They coordinated activities among themselves and with the instructor. Once the project was well underway during the summer (after class was over), additional funding was secured so that all three students who demonstrated commitment to the project, and the native Spanish-speaking teaching assistant (TA), were able to travel to Peru. In order to secure the additional funds, the instructor and the students worked on fundraising from various sources on campus. In one case, the students prepared a small proposal with the assistance of the instructor. These additional, non-technical activities required unanticipated extra work and skills; however, the students demonstrated commitment to the project and to each other by trying to raise enough funds for all volunteers to travel to Peru. The final water heater design was modular and the team planned to build five units in Peru. The main components of a single unit were built and tested before travel, while some materials and components were procured/pre-built for additional units to be assembled in the field. Students made many preparations, including packing the materials for the trip. The team's grit was tested somewhat during travel preparation but was tested more so during the implementation abroad.

\section{Method}

This investigation used a case study method that focused on an analysis of an individual section of a larger first year design course. ${ }^{21}$ Participants were 28 students taking the class and the TA for the section. Course enrollment was $11 \%$ female and $11 \%$ from ethnicities underrepresented in engineering which includes Latino, African American, and American Indian. Assessments included a course post-survey, observations from the course instructor, and a structured interview of two of the three students and the TA who traveled to implement the final design. The final design incorporated the most implementable features from those suggested by all of the FYEP class design teams. This step provided an incentive to all groups to come up with innovative design features worthy of implementation, even if their final design was not the one selected as the winner during the end-of-year design competition.

The course post-survey was composed of multiple choice questions and open-ended comment questions that addressed the research questions. The structured interview followed a series of questions and follow-up probes targeting the same research questions. ${ }^{22}$ The post-survey was administered the last week of class and the interviews were conducted with the travel team approximately 18 months later. Quantitative results were tallied and reported as percentages. Qualitative interview results were recorded and thematized together with open-ended responses. $^{23}$

Results

Quantitative and qualitative results will be discussed under each of the following research questions: 
1. Did the course develop an understanding of engineering for developing communities (EDC)?

2. Did the course topic motivate the students in the course to collaborate to solve problems?

3. Did the course motivate the students to travel to help these communities?

4. Did the course inspire students to pursue future EDC opportunities?

Understanding of EDC. Quantitative feedback from the post-course survey indicated that $76 \%$ of course participants thought they had an understanding of what engineering for developing communities was about. Student comments indicated a basic level of understanding as one student reported, "We are trying to invent and create resources that can be implemented in developing communities, and creating products that can function and be sustainable within those communities."

Analysis of interview data from the travel team indicated a more comprehensive knowledge of EDC gained through traveling to the developing community and implementing the design. The first theme to emerge from travel team interviews was the difficulty of designing in a developing community. One student reported, "There was a lot of work to be done. It was a good thing that all three of us went, because otherwise the project wouldn't have been able to be implemented."

Two subthemes emerged under this theme related to unexpected changes in the design plan and design constraints. Unexpected changes in the design plan seemed to be a continuous process for the travel team with one student reporting, "Very few things that we planned, happened," and another advising, "Design needs to be fool-proof and flexible. You need a plan B because it's likely that whatever can go wrong, will go wrong." Unexpected activities included having design materials confiscated by transportation security authorities; finding out that wood dimensions (e.g., 2" x 4") and tolerances were not the same in the developing community as in the US; and finding out that a key piece of the design, a pre-existing water tower, was not functioning as described by the community.

Another subtheme related to the difficulty of the design process described the design constraints, or lack thereof, that students had to operate under while in the developing community. Foremost was the lack of ready access to tools and supplies. One student reported, "The biggest challenge was to design a torch to solder together metal parts because you can't bring a torch on an airplane; I used a propane tank, added a hose, and tried that." Another student reported on, "the lack of regulations to guide design. In my internships, I always had to focus on safety and regulations; but in a developing community, not so much." This student fell back on his own ethics to deliver a safe design.

The second theme to emerge under an understanding of EDC was related to connecting with the community. One subtheme under this theme related to connecting with the travelling design team while another subtheme was focused on connecting with the local community. All of the travel team students recognized the need for a "good team," with one reporting that, "If there was conflict within the team, we would have not gotten it done. So, luckily we worked well together and realized that it was important to work together." Students met with the TA in the evening to plan events for the next day. 
While there was good design team cohesion, connections with the local community were variable. On the positive side, exposure to the developing community made students realize all the benefits of their home culture as one reported that the trip "shined a lot of light [on the fact] that most engineering goes towards the wealthiest and that this small contribution that I could make was very impactful to a community." However, students faced a language barrier with only one team member speaking the native language and even this member struggled with translating technical engineering terms to the community in their own regional dialect. The team was also unable to educate members of the school where they were working on their design, as planned, because the school was on winter break.

Observations from the instructor. Dealing with difficulties and unexpected challenges was commonplace in the field and students had to constantly adjust to negative circumstances and be flexible. In short, they had to rely on their grit on a regular basis to make progress on their project. After the first few days, their comfort with the adverse conditions for the project implementation increased. Their self-confidence and commitment to their work also increased as evidenced by their long work hours and excellent team work ethic, both within their team but also with their co-workers from Peru.

Impact of the course topic. Quantitative post-survey data indicated that $67 \%$ of course participants found the course topic more interesting than those from other sections of the course. Qualitative analysis of open-ended survey responses and travel team interviews indicated two themes in the data, one related to positive motivations generated by the course topic and another related to negative motivations.

Subthemes under positive motivation included the opportunity to serve people directly and the real world aspects related to the design being implemented in a developing community. One travel team member observed that the course topic "was motivating to those who want to help people with their designs," while another reported, "Other students cared a lot more for their design because it was for a real client." Another subtheme under positive motivations was the competitive aspect of the course with people motivated to turn out the winning design for "bragging rights."

Negative motivations around the course topic were centered on two subthemes, those who wanted more freedom to choose their design topic, and others who wanted a design topic specific to a different major than environmental engineering. One student described it, "In most sections of the course you get to choose what you want to do, but this class was different because all the teams were in competition against each other....It led to some wishing that groups had freedom to choose from a variety of project options."

Motivation to travel. From the course post-survey, $71 \%$ of students indicated that the course had sparked their interest in travelling to work in a developing community. Two themes emerged from the qualitative data analysis, one related to the chance to work abroad and the benefits that would accrue from this experience and another focused on the process one needed to go through to get the opportunity to travel.

Related to the first theme of being provided a chance to work abroad, subthemes related to a degree of excitement about the opportunity and the benefits of participating in this type of 
experience. Students in the class were, on average, excited about the prospect of taking their design forward and working abroad in a developing community with one reporting that the opportunity, "was a bit of a hook," and "When I found out someone would get to go, it was exciting." One student felt motivated to provide the following disclaimer on the team's travel experience by saying, "We were not tourists! We were extremely busy and incredibly stressed. It was a better way to connect with the culture - clearly an educational experience, but not a vacation."

Students were also aware of the benefits of an opportunity to work abroad on EDC. One reported, "If you get the chance to do work abroad, do it! It gives you insight and perspective of how things are done in other communities," while another described the value of, "being able to work on a global scale and being able to communicate effectively with people from other cultures and backgrounds." One travel team member acknowledged that he highlighted the benefits of learning to work with diverse cultures in his job interviews.

A second theme related to students' motivations to implement their design described the process for earning a spot on the travel team. One student commented, "It is important for students to know that there are opportunities available, and you have to work for it." Subthemes related to staying in touch with the instructor, taking leadership roles in class, and fundraising. In particular, fundraising was a barrier for a team of freshmen with one reporting, "We worked on one grant, but mostly the professor did the fundraising for us," and another reporting, "It was a pleasant surprise when the funding came in for all three [students] to go."

Pursuing EDC opportunities. Students in the course and the travel team were all queried on the likelihood of including engineering for developing communities in their future educational, service, and career goals. On the course survey, $67 \%$ of participants indicated an interest in future EDC coursework while all members of the travel team had developed an interest in incorporating EDC experiences. Themes in the data centered on educational impacts, extracurricular impacts, and career impacts.

Regarding education, a majority of students were interested in future EDC-type courses but there was a lack of awareness of future course opportunities. Another subtheme addressed the application of design concepts learned in the freshman class in future design courses with one reporting, "I'm now in a junior-level components design class...so now I realize that it's important to keep designs less complicated. Simplicity can be a good way to go."

Regarding extracurricular impacts, there was a theme of wanting to volunteer for these activities alongside a traditional engineering career. One student commented that he was, "looking for a traditional engineering internship, but I have become interested in a volunteer project to build a school in Nepal." Another student is working on an extracurricular project to build a bridge in Bolivia, and wants to travel every year for a project in a developing community.

Finally, there was a theme of incorporating EDC activities into one's career. The majority of the class was interested in EDC as a service or extracurricular activity and was looking for more traditional engineering career tracks, but there was curiosity about how one would include EDC into a traditional engineering career. 


\section{Discussion}

Based on our findings, focusing a first year design course on environmental EDC and offering an opportunity to implement the design proved an effective way to increase students' understanding of what it takes to engineer products for developing communities. The topic motivated some, but not all, students. As frequently occurs in a design class, some students wished that they were allowed to work on projects that they considered more relevant to their discipline or eventual career. Preparing for an engineering hardware implementation project in a distant location with limited resources appeared to increase perseverance, desire to use engineering skills to benefit society, and student attributes linked to grit including overcoming setbacks. ${ }^{16,17,18}$ Students who went beyond what was required by the class demonstrated a deeper understanding of the challenges involved with engineering in a developing community context. Those individuals took leadership roles in their in-class teams, connected with the professor throughout and after the semester, and noted an interest in volunteering to work on the design even after the class ended.

When funding became available for all of them to travel, the team was in a better position to work together because they had supported each other and had demonstrated that they were willing to make an effort towards the greater goal even if they were not the one who would eventually travel. This, in turn, may have allowed them to deal with the setbacks that they faced during project implementation. One of those setbacks involved a language barrier that existed, even for the student who spoke a different dialect of the local language. That experience appeared to lead to a realization by members of the travel team that successful engineering requires more than technical skills. The travel team recognized the importance of effective collaboration not only amongst themselves, but also with a Peruvian peer group of students who were implementing a complementary system at the same location, and members of the greater community where they were working. The team members recognized that they did not know how to connect with members of the community, and were disappointed when they missed an opportunity to interact with the larger community because of a scheduling misunderstanding.

\section{Implications}

Based on the responses of study participants, we believe that this first year design course focused on a service-learning project for an international developing community was valuable for building design skills, fostering grit, increasing professional interactions with diverse populations, developing an engineering identity, and improving multicultural communication skills. The course format motivated the majority of students to compete for "bragging rights" as well as to collaborate to improve the winning design so that it best met the needs of the community where it would be implemented. For that reason, the instructor feels that this was a valuable learning experience for both the majority and underrepresented members of her class. Only time will tell whether or not this instructor's section of the design course will draw increasing numbers of Latino students due to word-of-mouth recruiting from students who enjoyed the project.

With respect to whether the course motivated students to pursue future EDC opportunities, our findings show that it did. However, one takeaway from this study is that students need more information regarding the possibilities of how to incorporate engineering for developing 
communities into a career plan. They also need more information about what it takes to prepare for international travel, whether that is for work or for volunteer experiences such as this.

\section{Limitations and Future Research Opportunities}

Sample sizes in this study are small due to the lack of underrepresented students who enroll in engineering at our university and because we are using a case study method that focused on one section of a larger course. Therefore, the quantitative results should be considered tentative. To dig deeper into the motivational impact of the topic itself compared to having an opportunity to travel to a developing community for project implementation, the authors intend to conduct a comparative study that includes surveys gathered during a subsequent offering of the same course, with the same topic and instructor, but without an opportunity for any of the students to travel for project implementation.

\section{Concluding Remarks}

This case study investigated the impact of a particular course topic and context, engineering for developing communities, on the knowledge and motivations of students enrolled in the course. Results indicated that students in the course developed a basic understanding of EDC, but that members of the travel team developed a deeper level of understanding centered around the grit involved in implementing their design and interactions with the various communities participating.

Students were also assessed for their motivations to engage in the course topic, travel to help the community, and pursue further EDC career opportunities. Students in the course who were motivated to help others and compete with their designs were motivated by the topic, but other students desired a topic more central to their major. Students in the course were also motivated to travel and do EDC and pursue additional EDC career opportunities, but they were not always aware of the opportunities available or how to fund them. Travel team members overcame these limitations through their own grit and perseverance.

This course section and one other tied for having the most Latino students of any section, although numbers were small and additional research is needed to determine the influence of the course on underrepresented populations. Additional research will also focus on the impact of a section of the course without a travel opportunity to see if the same outcomes are observed.

Overall, results indicated that the course topic provided a worthy context for learning about design and engineering for developing communities and motivating students to further explore this topic. Impacts seemed much more pervasive for the travel team than the general class, so initial recommendations, pending further research, are to continue to include this component in future offerings of the course. 


\section{Bibliography}

${ }^{1}$ National Academy of Engineering. NAE Grand Challenges for Engineering. Grand Challenges -- Engineering Challenges. [Online] n.d. (Accessed November 13, 2012).

${ }^{2}$ Bureau of Labor Statistics, U.S. Department of Labor, Occupational Outlook Handbook, 2012-13 Edition, Environmental Engineers, on the Internet at http://www.bls.gov/ooh/architecture-andengineering/environmental-engineers.htm (Accessed November 13, 2012).

${ }^{3}$ Zarske, M., D. Reamon, D. Knight, and Bielefeldt, A. (2012). Service-based first Year engineering projects: Do they make a difference? American Society for Engineering Education (ASEE) Annual Conference and Exposition Proceedings. Community Engagement in Engineering Education Constituent Committee Division. June 10-13. San Antonio, TX.

${ }^{4}$ Knight, D. W., Carlson, L. E., and J. F. Sullivan. (2003). "Staying in Engineering: Impact of a Hands-On, TeamBased, First-Year Projects Course on Student Retention," Proceedings of the 2003 American Society for Engineering Education Annual Conference \& Exposition, ASEE 2003, Session 3553.

${ }^{5}$ Richardson, J. and Dantzler, J., Effect of a Freshman Engineering Program on Retention and Academic Performance, Frontiers in Education Conference Proceedings, ASEE/IEEE, 2002, S2C-16 - S2C-22.

${ }^{6}$ National Research Council. Educating the engineer of 2020: Adapting engineering education to the new century. Washington, DC: The National Academies Press, 2005, 53.

${ }^{7}$ National Service-Learning Clearinghouse, http://www.servicelearning.org/what-is-service-learning (Accessed November 30, 2012)

${ }^{8}$ Bordas, J. (2007). Salsa, soul, and spirit: Leadership for a multicultural age. San Francisco, CA: Berrett-Koehler.

${ }^{9}$ McDermottt M. (2008). Book review: Juana Bordas' (2007) Salsa, soul, and spirit: Leadership for a multicultural age." International Journal of Leadership Studies, 4(1), 120-124.

${ }^{10}$ Mullan F., Chen C., Petterson S., Kolsky G., and Spagnola M. (2010). The social mission of medical education: ranking the schools. Ann Intern Med. 152, 804-811.

${ }^{11}$ Lee T.S. (2009). Building Native Nations through Native Students' Commitment to Their Communities. Journal of American Indian Education, 48(1), 19-36.

${ }^{12}$ Hurtado A. (2009). Lifting as we claim in Social Identities and Social Action. Mexicans in California Transformations and Challenges.

${ }^{13}$ Passel, J. S., and Cohn, D. (2008, February 11). US population projections: 2005-2050. Washington, D.C.: Pew Hispanic Center.

${ }^{14}$ Lord S.M., Madsen Camacho M., Layton R.A., Long R.A., Ohland, M.W., and Wasburn, M.H. (2009). Who’s persisting in engineering? A comparative analysis of female and male Asian, Black, Hispanic, Native American, and White students. Journal of Women and Minorities in Science and Engineering, 15, 167-190.

${ }^{15}$ Zarske, M., Reamon, D., Bielefeldt, A. R., and Knight, D. (2012). Service-based first-year engineering projects: Do they make a difference? Society for Engineering Education (ASEE) Annual Conference and Exposition Proceedings. American Society of Engineering Education.

${ }^{16}$ Duckworth A.L., Peterson C., Matthews M.D., and Kelly D.R. (2007). Grit: Perseverance and Passion for LongTerm Goals. Journal of Personality and Social Psychology, 92(6), 1087-1101.

${ }^{17}$ Jaeger B., Freeman S., Whalen R., and Payne R. (2010). Successful students: Smart or tough?, Proceedings of the 2010 American Society for Engineering Education Annual Meeting. 
${ }^{18}$ Dweck, C.S. (2006). Mindset: The New Psychology of Success, New York: Random House

${ }^{19}$ Knight, Daniel W., Lawrence E. Carlson, and Jacqueline F Sullivan. (2003). "Staying in Engineering: Impact of a Hands-on, Team-Based, First-Year Projects Course on Student Retention." Proceedings of the 2003 ASEE Annual Conference and Exposition, Nashville, TN, page Session 3553. Washington, DC: American Society for Engineering Education, 2003. http://itll.colorado.edu/images/uploads/about us/publications/Papers/ ASEE\%2003\%20Retention\%20GEEN\%201400\%20Proceedings.pdf

${ }^{20}$ Regents of the University of Colorado, Office of Planning, Budget and Analysis. (2012). Fall enrollment by college, major, ethnic group, class level. Available online at http://www.colorado.edu/pba/div/inrdsf12.xlsx. Accessed December 28, 2012.

${ }^{21}$ Cook, T.D. and Campbell, D.T. (1979). Quasi-experimentation: Design \& analysis issues for field settings. Boston: Houghton Mifflin Company.

${ }^{22}$ Creswell, J.W. (2009). Research design: Qualitative, quantitative, and mixed methods approaches. Los Angeles: SAGE.

${ }^{23}$ Lacey, A. and Luff, D. (2001). Trent Focus for Research and Development in Primary Health Care: An Introduction to Qualitative Analysis. Trent Focus Group. 